\title{
A flow cytometric assay for the study of dense granule storage and release in human platelets.
}

A Sofia Ramström, I Fagerberg and Tomas Lindahl

\section{Linköping University Post Print}

N.B.: When citing this work, cite the original article.

Original Publication:

AS Ramström, I Fagerberg and Tomas Lindahl, A flow cytometric assay for the study of dense granule storage and release in human platelets., 1999, Platelets, (10), 2, 153-158.

Copyright: Informa Healthcare

http://informahealthcare.com/

Postprint available at: Linköping University Electronic Press

http://urn.kb.se/resolve?urn=urn:nbn:se:liu:diva-25010 


\section{A FLOW CYTOMETRIC ASSAY FOR THE STUDY OF DENSE GRANULE STORAGE AND RELEASE IN HUMAN PLATELETS}

A. S. Ramström, I. H. Fagerberg, T. L. Lindahl

Department of Biomedicine and Surgery, Division of Clinical Chemistry, Linköping University Hospital, S-581 85 Linköping Sweden

Running title: Dense Granule Analysis by Flow Cytometry

Correspondence to: T.L. Lindahl. Tel: +46 13223227 Fax: +46 13223240 E-mail:

tomas.lindahl@klk.us.lio.se 


\section{Summary}

The clinical manifestations of platelet dense $(\delta)$ granule defects are easy bruising as well as epistaxis and bleeding after delivery, tooth extractions and surgical procedures. The observed symptoms may be explained either by a decreased number of granules or by a defect in the uptake/release of granule contents. We have developed a method to study platelet dense granule storage and release. The uptake of the fluorescent marker, mepacrine, into the platelet dense granule was measured using flow cytometry. The platelet population was identified by the size and binding of a phycoerythrin-conjugated antibody against GPIb. Cells within the discrimination frame were analysed for green (mepacrine) fluorescence. Both resting platelets and platelets previously stimulated with collagen and the thrombin receptor agonist peptide SFLLRN was analysed for mepacrine uptake. By subtracting the value for mepacrine uptake after stimulation from the value for uptake without stimulation for each individual, the platelet dense granule release capacity could be estimated.

Whole blood samples from 22 healthy individuals were analysed. Mepacrine incubation without previous stimulation gave mean fluorescence intensity (MFI) values of $83 \pm 6$ (mean $\pm 1 \mathrm{SD}$, range 69-91). The difference in MFI between resting and stimulated platelets was $28 \pm 7$ (range 17-40). Six members of a family of whom one had a known $\delta$-storage pool disease were analysed. The two members (mother and son) who had prolonged bleeding times also had MFI-values disparate from the normal population in this analysis. The values of one daughter with mild bleeding problems but a normal bleeding time were in the lower part of the reference interval.

Introduction 
Defects in platelet granules ("storage pool deficiencies") have been reported both for dense granules $(\delta)$ and $\alpha$ granules, separately and combined ${ }^{1}$. The observed symptoms may be explained either by the absence or decreased number of granules or by a defect in the uptake/release of granule contents ${ }^{2}$. Acquired storage pool disorders were also found, often associated with in vivo platelet activation ${ }^{3} . \delta$-storage pool deficiency may occur as a single abnormality or as part of inherited disorders such as the HermanskyPudlak, Chediak-Higashi and Wiskott-Aldrich syndromes ${ }^{1}$. The clinical manifestations are easy bruising as well as epistaxis and bleeding after delivery, tooth extractions and surgical procedures ${ }^{2}$. Severe haemorrhage is rare except after ingestion of anti-platelet drugs such as aspirin. The inheritance of the defect is unclear, although it is possible that several different genetic alterations causes the same defect ${ }^{1}$.

Platelets in patients with $\delta$-storage pool disease contain less adenine nucleotides than normal platelets, and the serotonin content varies. Morphological examination shows that the platelets look rather normal except for the decrease or absence of dense bodies ${ }^{1}$. Routine methods give variable results among patients with $\delta$-storage pool deficiency, and even in the same patient at different points of time. The bleeding time is usually prolonged, but this as well as the aggregation of platelets may be normal ${ }^{1}$. Thirty-five percent of a patient group with prolonged bleeding time but normal aggregation patterns and normal von Willebrand factor levels were shown to have a decreased release of ATP and decreased numbers of dense granules ${ }^{4}$.

To study the number of dense granules visually in individual platelets is an alternative to the studies of release from dense granules. The dense character of the granules make them visible in transmission electron microscopy without any staining ${ }^{4}$. Uranaffin or osmium staining might, however, accentuate the abnormalities ${ }^{1}$. Mepacrine (also called 
quinacrine) is a fluorescent acridine derivative which binds with high affinity to adenine nucleotides and is rapidly and selectively taken up by platelet dense granules ${ }^{2,5,6}$. In other cells such as monocytes, mepacrine accumulates in lysosomes, but in platelets only the dense bodies are stained ${ }^{7}$. Mepacrine-treated platelets from patients with dense granule abnormalities have earlier been investigated with fluorescent microscopy to determine the number of dense granules ${ }^{8,9}$. The development of the flow cytometer opened a new possibility of studying platelet dense granules with mepacrine in a simple and rapid way. This has been described both using whole blood ${ }^{10}$ and platelet rich plasma $(\mathrm{PRP})^{2}$. Both studies have reported reduced staining of platelets from patients with $\delta$-storage pool disease compared with the staining of platelets from normal controls. In both articles the diagnosis is based on mepacrine uptake by unstimulated platelets, although the thrombin-induced release of mepacrine from platelets of a patient with Hermansky-Pudlak syndrome was reported to be reduced when compared with normals ${ }^{10}$. Our objective was to modify the method to include both dense granule uptake and release, which would make it possible to identify both patients with defects in the number of dense granules and patients with defects in the release from dense granule. This is important since both of these abnormalities may lead to the symptoms characteristic for $\delta$-storage pool disease.

Materials and methods

\section{Reagents and antibodies}

Hanks balanced salt solution without $\mathrm{Ca}^{2+}$ and $\mathrm{Mg}^{2+}$ (Hanks BSS) and chemicals for the HEPES buffer $\left(137 \mathrm{mmol} / \mathrm{L} \mathrm{NaCl}, 2.7 \mathrm{mmol} / \mathrm{L} \mathrm{KCl}, 1 \mathrm{mmol} / \mathrm{L} \mathrm{MgCl}_{2}, 5.6 \mathrm{mmol} / \mathrm{L}\right.$ glucose, $1 \mathrm{~g} / \mathrm{L}$ bovine serum albumin and $20 \mathrm{mmol} / \mathrm{L}$ HEPES, $\mathrm{pH} 7.40)^{11}$ were 
purchased from Sigma Chemical Company (Saint Louis, Missouri, USA). The thrombin receptor agonist peptide SFLLRN was a generous gift from Prof. N Solum, Oslo, Norway, and the collagen was kindly provided by Beate Kehrel, Münster, Germany ${ }^{12}$. Mouse anti-GPIb-phycoerythrin antibody was purchased from Dako AS (Glostrup, Denmark). Quinacrine mustard dihydrochloride $\left(\mathrm{C}_{23} \mathrm{H}_{28} \mathrm{Cl}_{3} \mathrm{~N}_{3} \mathrm{O} \times 2 \mathrm{HCl}\right.$, mepacrine, Sigma Chemical Company) was prepared as a $0.5 \mathrm{mmol} / \mathrm{L}$ solution in Hanks BSS. The powder was dissolved in $100 \mu \mathrm{L}$ of DMSO before the addition of Hanks BSS, and the solution was kept at $37^{\circ} \mathrm{C}$ (water bath) until it became transparent. The solution was portioned and kept at $4^{\circ} \mathrm{C}$. The GPIIb/IIIa antagonist MK-852 was generously provided by Merck, Sharp \& Dohme (West Point, PA, USA) ${ }^{13}$.

\section{Patients and controls}

22 healthy volunteers without bleeding tendency were examined (14 males, 8 females, ages 22-60). All participants were informed about the aims of the study and accepted participation. No medication with a potential of interfering with platelet function was allowed for 10 days before blood sampling.

The six patients were from a family in which several members showed symptoms of impaired platelet function. We examined the mother, age 48 , her son, age 8 , her twin daughters, age 9, and a daughter, age 25 . The elder daughter was married to her cousin, age 32 , who was included as he was also reported to have problems. The son and the mother had serious bleeding problems, one of the twin daughters showed mild symptoms and the other had no symptoms. The elder daughter had experienced a cerebral haemorrhage. When investigated in Malmö 1993, the eight years old son and another son, age 19, were diagnosed with storage pool disease as they showed reduced platelet adhesiveness and an absence of a secondary aggregation wave in response to 
ADP.

Blood collection

Venous blood was collected in $5 \mathrm{~mL}$ vacuum tubes (Vacutainer ${ }^{\circledR}$ system, Becton

Dickinson, Rutherford, NJ) containing $0.5 \mathrm{ml} 0.129 \mathrm{~mol} / \mathrm{L}$ sodium citrate.

\section{Mepacrine labelling}

The labelling was performed 1.5 hours after blood sampling. Before the start of the labelling procedure, the blood samples were gently mixed for at least 10 minutes. Sixty $\mu \mathrm{L}$ of blood was diluted 1:40 in HEPES buffer. Three hundred $\mu \mathrm{L}$ of diluted blood was portioned in 6 plastic tubes. Ten $\mu \mathrm{L}$ of anti-GPIb-phycoerythrin antibody (diluted 1:5) was added to all tubes. Then $60 \mu \mathrm{L}$ of HEPES buffer was added to the first four tubes, and $30 \mu \mathrm{L}$ each of SFLLRN (final concentration $4.9 \mu \mathrm{g} / \mathrm{mL}$ ) and collagen (final concentration $0.27 \mu \mathrm{g} / \mathrm{mL}$ ) were added to the last two tubes. The additions of SFLLRN and collagen had to be performed separately, as their stimulating effects were decreased if they were mixed in advance. Gentle stirring followed every addition. Exactly 10 minutes after the first addition, $55 \mu \mathrm{L}$ of HEPES buffer was added to the two first tubes and $55 \mu \mathrm{L}$ of mepacrine mustard solution (final concentration $65 \mu \mathrm{mol} / \mathrm{L}$ ) to the other four tubes. The tubes were stirred and placed in the dark at $37^{\circ} \mathrm{C}$ (in a water bath) directly after addition. Exactly 30 minutes after the addition of HEPES/mepacrine, the tubes were stirred and $50 \mu \mathrm{L}$ of the sample was diluted 1:20 in HEPES buffer and then kept in the dark until analysed. All samples were analysed within four hours. To check if aggregation occurred during the stimulation, $1 \mu \mathrm{g} / \mathrm{mL}$ of the platelet inhibitor MK-852 was added to the 1:40 dilution 10 minutes before the start of the mepacrine labelling procedure described above. A sample without MK-852 was prepared and run in parallel. This was repeated three times. 


\section{Flow cytometry}

The analyses were performed with a Cytoron Absolute flow cytometer (Ortho, Raritan, NJ, USA). The light scattering properties and red fluorescence from the anti-GPIbphycoerythrin antibody identified the platelet cluster, and a discrimination frame was placed around it. All particles inside the frame were analysed for green (mepacrine) fluorescence. A gate was set to divide the platelets in the mepacrine unmarked samples so that $97-98 \%$ of the platelets were "negative" (i.e. "gated in region 1") and 1-2\% "positive" (i.e. "gated in region 2") for green fluorescence (background values). The mepacrine-marked samples were checked for their percentage of cells gated in region 2. The mean fluorescence intensity (MFI) for all cells within the discrimination frame was also recorded. One thousand cells were investigated in each sample. All samples were run in duplicate. In the experiments with and without MK-852 all samples were run in triplicate. In these samples both the MFI values and the platelet concentration after the labelling procedure were investigated.

Results

Unstimulated platelets were incubated for 30 minutes at $37{ }^{\circ} \mathrm{C}$ with $0.16-122 \mu \mathrm{mol} / \mathrm{L}$ of mepacrine. Sixty-five $\mu \mathrm{mol} / \mathrm{L}$ of mepacrine was shown to be suitable for the detection of all of the variations encountered in this study. Mepacrine solution stored for up to four months at $4{ }^{\circ} \mathrm{C}$ gave similar staining results as fresh mepacrine solution. Analyses of blood samples were performed 0.5, 1, 2, 4 and 24 hours after blood sampling. The staining of platelets was rather constant for the first four hours. After 24 hours the staining after stimulation was higher, but the staining without stimulation did not differ from the values obtained within four hours (data not shown). Since other 
platelet function analyses performed in this laboratory have revealed that the platelet stimulation capacity is optimal 1.5 hours after blood collection, that time point was chosen for this analysis as well.

\section{Dense granule uptake and release in normal platelets}

Blood samples from 22 healthy individuals were analysed as described in "Materials and methods" and the results are presented in table 1 . The individual variations in staining were great, but individuals with few stained cells without stimulation were often also shown to have low staining values after stimulation, i.e. a normal release of dense granule contents. Therefore, we calculated the quotient (stained cells after stimulation/stained cells without stimulation) for each individual. We also calculated the difference between stained cells before and after stimulation. The differences gave the best discrimination between patients with symptoms and normal individuals (data not shown), and were therefore chosen for further comparisons. Coefficients of variation calculated on duplicates were $3.5 \%$ for the percentage stained cells without stimulation and $9.9 \%$ for the values after stimulation. The coefficients for the MFI values were 1.4 and $2.2 \%$, respectively.

Blood samples from one of the volunteers were analysed on five separate occasions within a period of ten months. The inter-assay variation for the MFI values, including biological variation, was $1.3 \%$ for the staining without stimulation, $8.5 \%$ for the staining after stimulation and $15.9 \%$ for the differences. The intra-assay variation for the duplicates was below $2 \%$.

To check if the stimulation of the platelets caused aggregation, three samples were run in parallel with and without the platelet inhibitor MK-852. The MFI values and the platelet concentrations were recorded. The cell count decreased slightly after 
stimulation, $6.2 \pm 0.4 \%$ for the samples without inhibitor and $4.4 \pm 1.2 \%$ (mean \pm 1 SD) for the samples with inhibitor. The MFI values after stimulation were slightly higher in the samples without inhibitor, which caused lower difference values, $11.7 \pm 1.9 \%$.

\section{Examination of six patients with suspected $\delta$-storage pool disease}

Six patients were investigated using the same method as for the normal individuals. Of these, two (the mother and her son) were shown to have increased bleeding times (according to the modified Ivy-technique) and thrombocytopenia $\left(101 \times 10^{9}\right.$ and $115 \times$ $10^{9}$ cells/L, respectively). The mean fluorescence intensities recorded for the patients are shown in table 2 together with the reference intervals obtained from the results from the normal individuals. The son born in 1989 is the only one with abnormal staining values without stimulation. When examining the differences, however, both the mother and this son had values deviating from the normal population, and the twin sister with reported problems and the elder daughter had values in the lower part of the reference interval (see figures 1 and 2).

\section{Discussion}

The method described in this study determines both the platelet content of dense granules and the amount of dense granules capable of degranulation in response to a given stimulus in a rapid and simple way.

The mean fluorescence intensity varies less than the percentage of positive cells in the group of healthy individuals studied. Therefore, it seems reasonable to express the results as MFI of all platelets investigated in each sample. There is also better discrimination between the patients with bleeding problems and the healthy individuals when examining MFI values instead of percentage positive cells (data not shown). 
By comparing the staining of stimulated and unstimulated platelets we were able to identify one patient (the mother, patient 1 in fig. 1 and 2), who had normal staining without stimulation but who did not release a normal amount of granule contents upon stimulation. This patient would have been classified as normal in analyses performed as previously described ${ }^{2,10}$, since defects in the release reaction were not detected there. Compared with electron microscopy, the flow cytometric method is much less timeconsuming, the sample preparation is easier and the counting of cells is more rapid. Furthermore, the special equipment and competence required for electron microscopy are not available everywhere. The rapid counting is also an advantage as compared with fluorescent microscopy of mepacrine treated platelets. One thousand cells in each duplicate sample were counted here, as compared with studies with fluorescent microscopy, where only about 50 cells per individual were examined ${ }^{8,9}$. The diagnosis of dense granule defects by aggregometry ${ }^{1}$ has not been successful in all cases $^{4}$, since some patients manifested normal aggregation patterns. The advantages detected with this flow cytometric method suggest that it should be a good complement to the platelet function tests performed in laboratories world-wide as a fast, simple and reliable assay for dense granule function.

\section{Acknowledgements}

This work was supported by the Swedish Foundation for Strategic Research as a project within the Linköping Graduate School in Biomedical Research, and by the county of Östergötland.

\section{References}


1. Coller BS. Inherited disorders of platelet function. In: Bloom AL, Forbes CD, Thomas DP, Tuddenham EGD. Haemostasis and Thrombosis 3:rd ed. Edinburgh: Churchill Livingstone, 1994: 721-66

2. Gordon N, Thom J, Cole C, Baker R. Rapid detection of hereditary and acquired platelet storage pool deficiency by flow cytometry. Br J Haematol 1995; 89:117-23

3. Warkentin TE, Kelton JG. Aquired platelet disorders. In: Bloom AL, Forbes CD, Thomas DP, Tuddenham EGD. Haemostasis and Thrombosis 3:rd ed. Edinburgh: Churchill Livingstone, 1994: 767-818

4. Israels SJ, McNicol A, Robertson C, Gerrard JM. Platelet storage pool deficiency: diagnosis in patients with prolonged bleeding times and normal platelet aggregation. Br J Haematol 1990; 75:118-21

5. Da Prada M, Pletscher A. Accumulation of basic drugs in 5-hydroxytryptamine storage organelles of rabbit blood platelets European J Pharmacol 1975; 32:179-85

6. Lorez HP, Da Prada M, Rendu F, Pletscher A. Mepacrine, a tool for investigating the 5-hydroxytryptamine organelles of blood platelets by fluorescence microscopy $J L a b$ Clin Med 1977; 89(1):200-6

7. Skaer RJ, Flemans RJ, McQuilkan S. Mepacrine stains the dense bodies of human platelets and not platelet lysosomes. Br J Haematol 1981; 49:435-8

8. Rendu F, Nurden AT, Lebret M, Caen JP. Relationship between mepacrine-labelled dense body number, platelet capacity to accumulate $14 \mathrm{C}-5-\mathrm{HT}$ and platelet density in the Bernard-Soulier and Hermansky-Pudlak syndromes. Thrombos Haemostas 1979; 42:694-704 
9. Lorez HP, Richards JG, Da Prada M, Picotti GB, Pareti FI, Capitanio A, Mannucci PM. Storage pool disease: Comparative fluorescence microscopical, cytochemical and biochemical studies on amine-storing organelles of human blood platelets $\mathrm{Br} J$ Haematol 1979; 43:297-305

10. Wall JE, Buijs-Wilts M, Arnold JT, Wang W, White MM, Jennings LK, Jackson CW. A flow cytometric assay using mepacrine for study of uptake and release of platelet dense granule contents. Br J Haematol 1995; 89:380-5

11. Lindahl TL, Festin R, Larsson A. Studies of fibrinogen binding to platelets by flow cytometry: An improved method for studies of platelet activation Thrombos Haemostas 1992; 68(2):221-5

12. Kehrel B, Wierwille S, Clemetson KJ, Anders O, Steiner M, Knight CG, Farndale RW, Okuma M, Barnes MJ. Glycoprotein VI is a major collagen receptor for platelet activation: it recognizes the platelet-activating quaternary structure of collagen, whereas CD36, glycoprotein IIb/IIIa, and von Willebrand factor do not. Blood 1998; 91(2):491-9

13. Larsson A, Lindahl TL. Inhibition of fibrinogen binding to platelets by MK-852, a new GPIIb/IIIa antagonist. Ups J Med Sci 1994; 99(2):121-130 
Table 1:

\begin{tabular}{|c|c|c|c|c|}
\hline & \multicolumn{2}{|c|}{$\%$ positive cells } & \multicolumn{2}{|c|}{$\begin{array}{l}\text { Mean fluorescence intensity } \\
\text { (MFI) }\end{array}$} \\
\hline & mean $\pm 1 \mathrm{SD}$ & Range & mean $\pm 1 \mathrm{SD}$ & range \\
\hline $\begin{array}{l}\text { Without } \\
\text { stimulation }\end{array}$ & $66 \pm 10$ & $41-79$ & $83 \pm 6$ & $69-91$ \\
\hline After stimulation & $18 \pm 8$ & $7-38$ & $55 \pm 6$ & $47-67$ \\
\hline $\begin{array}{l}\text { Quotient } \\
\text { (after/without } \\
\text { stimulation) }\end{array}$ & $0.27 \pm 0.11$ & $0.11-0.51$ & $0.66 \pm 0.07$ & $0.55-0.78$ \\
\hline $\begin{array}{l}\text { Difference } \\
\text { (without - after } \\
\text { stimulation) }\end{array}$ & $48 \pm 8$ & $30-64$ & $28 \pm 7$ & $17-40$ \\
\hline
\end{tabular}

Table 2:

\begin{tabular}{|l|l|l|l|}
\hline Patient & $\begin{array}{l}\text { MFI without stimulation } \\
\text { (mean of duplicate } \\
\text { measurements) } \\
\text { Reference interval: 71-95 }\end{array}$ & $\begin{array}{l}\text { MFI difference } \\
\text { (mean of duplicate } \\
\text { measurements) } \\
\text { Reference interval: } \\
14-42\end{array}$ & $\begin{array}{l}\text { MFI quotient } \\
\text { (mean of duplicate } \\
\text { measurements) } \\
\text { Reference interval: } \\
0.52-0.8\end{array}$ \\
\hline 1 female, born in 1949) & 80 & 9 & 0.88 \\
\hline 2 (male, born in 1989) & 58 & 12 & 0.8 \\
\hline 3 (female, born in 1988) & 80 & 15 & 0.82 \\
\hline 4 (female, born in 1988) & 81 & 25 & 0.7 \\
\hline 5 (female, born in 1972) & 83 & 17 & 0.8 \\
\hline 6 (male, born in 1965) & 84 & 28 & 0.67 \\
\hline
\end{tabular}


Legends:

Figure 1. Mean fluorescence intensity (MFI) for unstimulated platelets incubated with $65 \mu \mathrm{M}$ of mepacrine for 30 minutes at $37^{\circ} \mathrm{C}$. The values for 22 healthy volunteers are seen in the left column. The values for the six family members with suspected $\delta$-storage pool disease examined in this study are shown in the right column.

Figure 2. Differences between mepacrine uptake by unstimulated platelets and platelets stimulated by collagen and the thrombin receptor agonist peptide SFLLRN for 10 minutes before incubation with $65 \mu \mathrm{M}$ of mepacrine for 30 minutes at $37^{\circ} \mathrm{C}$. The MFI difference values for 22 healthy volunteers are seen in the left column. The values for the six family members with suspected $\delta$-storage pool disease examined in this study are shown in the right column.

Table 1. Results from the examination of platelets from 22 healthy individuals by the method described in "Materials and Methods". The results are expressed both as \% positive cells and mean fluorescence intensity.

Table 2. MFI values for six members of a family with suspected $\delta$-storage pool disease. The reference intervals given are mean values for the healthy individuals \pm 2 SD. 


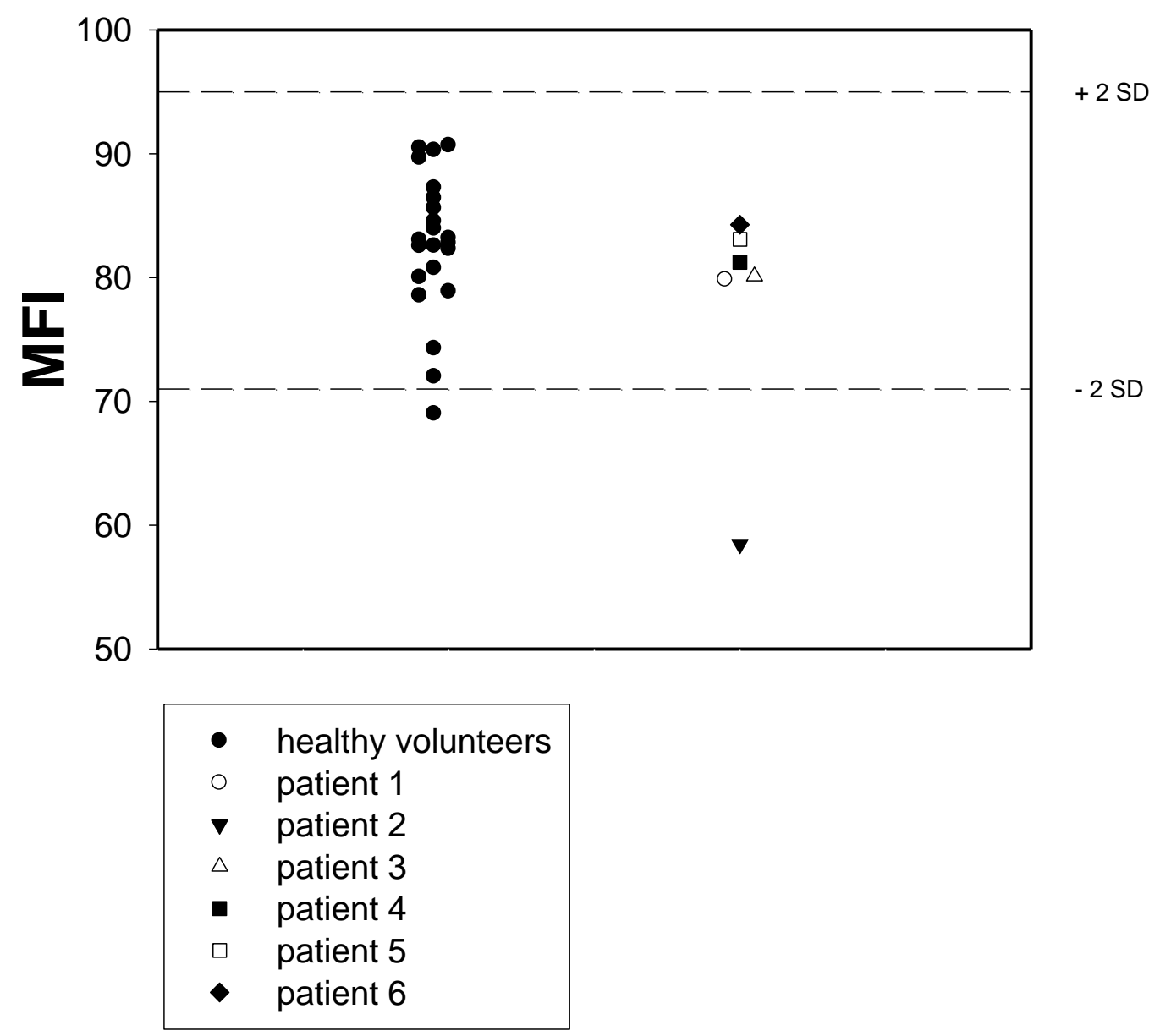




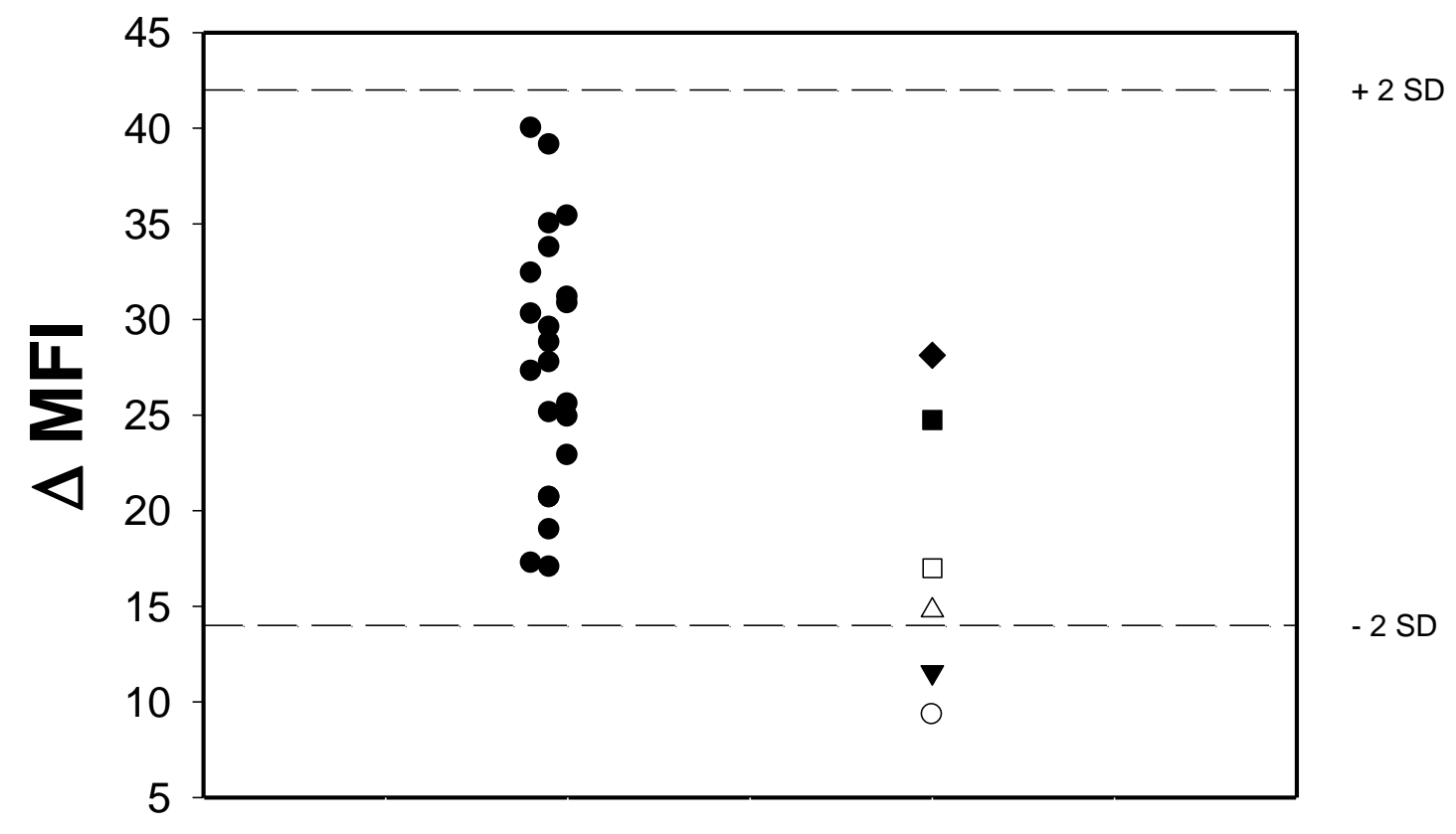

- healthy volunteers

- patient 1

$\nabla$ patient 2

$\triangle$ patient 3

- patient 4

$\square \quad$ patient 5

- patient 6 